\title{
Crise e elementos de saída política para a classe trabalhadora sob o governo Bolsonaro
}

Gonzalo Adrián Rojas ${ }^{1}$

Shimenny Ludmilla Araújo Wanderley²

\section{Resumo}

No marco da crise do capitalismo mundial e dos ataques à classe trabalhadora no Brasil, este artigo tem uma introdução, três partes e uma conclusão. Na primeira caracterizamos o governo Bolsonaro, o que tem influência no tipo de luta contra ele e o regime político que permitiu sua ascensão. Na segunda diferenciamos frente única operária nos termos dos quatro primeiros congressos da III Internacional do que, no Brasil, se conhece em termos genéricos como frente ampla sem delimitação de classe. Para, na terceira parte, apresentar a necessidade de organização política da classe trabalhadora com um conjunto de propostas transicionais como saída.

\section{Palavras chave}

Brasil; governo Bolsonaro; Crise orgânica; Propostas transicionais.

Crisis and elements of political exit for the working class under the Bolsonaro government

\begin{abstract}
In the context of the crisis of capitalism and the attacks on the working class in Brazil, this article has an introduction, three parts and a conclusion. In the first, we characterize the Bolsonaro government, which influences the type of struggle against it and the political regime. In the second, we differentiate the workers' united front in terms of the congresses of the III International from what is known in Brazil in general terms as a broad front without class delimitation. For the third part the need for political organization of the working class with a set of transitional proposals.
\end{abstract}

\section{Keywords}

Brazil; Bolsonaro government; Organic crisis; Transitional proposals.

Artigo recebido em junho 2020

Artigo aprovado em agosto de 2020 


\section{Introdução}

Estamos vivenciando desde o ano 2008 uma crise orgânica do capitalismo mundial que se manifesta de forma desigual e combinada em cada país, em cada formação econômico-social onde, a partir do ano 2020, temos uma crise sanitária que aprofunda a crise econômica, política e social que já estava em curso.

Isso deu lugar a um conjunto de fenômenos na geopolítica mundial que se manifestam também no Brasil. O fim do consenso globalizador no marco da crise abriu espaço à tentativas instáveis de superá-la, no sentido da extrema direita, fortalecendo elementos nacionalistas na principal potência imperialista com o triunfo de Donald Trump e, no Brasil, com o triunfo eleitoral, após o golpe institucional e do governo de Michel Temer, de Jair Bolsonaro.

Consideramos que vivenciamos, em termos leninistas, o período do imperialismo, que articula complexos momentos de crises, guerras e revoluções.

No caso do Brasil, observamos desde antes do golpe institucional, e apresentado isto com total independência política da política de conciliação de classes do Partido dos Trabalhadores (PT) e seus governos, um aprofundamento dos ataques à classe trabalhadora.

Estes ataques, mudança nas leis trabalhistas, reforma da previdência, lei de teto dos gastos em benefício do pagamento da espúria dívida interna, entre outros, realizados com a passividade das centrais sindicais, têm como objetivo mudar a correlação de forças entre as classes para garantir ainda mais os lucros do capital financeiro e de forma mais acelerada.

Se procura a fragmentação da classe trabalhadora para explorar mais e melhor, dividindo entre trabalhadores formais e informais, com certos direitos, e terceirizados, empregados e desempregados, uberizando e precarizando ainda mais a classe e deixando sem perspectiva a grande maioria da juventude. 
Frente a isso, este artigo tem três partes. Na primeira buscamos caracterizar o governo Bolsonaro porque, dependendo de como se caracteriza, se desprende o tipo de luta que se realiza contra ele ou contra o regime político que permitiu sua ascensão. Na segunda parte diferenciamos frente única de trabalhadores, frente única operária nos termos dos quatro primeiros congressos da III Internacional do que, no Brasil, se conhece em termos genéricos como frente ampla sem delimitação de classe. Para, na terceira parte, apresentar a necessidade de organização política da classe trabalhadora como uma estratégia revolucionária para vencer, desde a perspectiva da luta de classes, superando não só os ataques de Bolsonaro, senão também de Mourão, os militares e os golpistas e seu legado.

\section{Caracterizando o governo Bolsonaro}

León Trotsky no seu artigo Bonapartismo e fascismo, escrito em 15 de julho de 1934, expõe a grande importância prática de uma orientação política correta que se manifesta com mais evidência nas épocas de conflitos sociais agudos, de rápidos giros políticos ou de mudanças repentinas na situação. De acordo com o líder da Revolução Russa de outubro de 1917 junto com Vladimir Ilitch Lenin:

Nestas épocas, as concepções e generalizações políticas são rapidamente superadas e exigem sua substituição por completo - o que é mais fácil - ou sua concretização, precisão ou retificação parcial - o que é mais difícil-. Precisamente nestes períodos surgem necessariamente todo tipo de combinações e situações transitórias, intermediárias, que superam os padrões habituais e exigem atenção teórica contínua e redobrada. Em uma palavra, se na época pacífica e "orgânica" (antes da guerra) até poderia-se viver às custas de algumas abstrações pré-concebidas, na nossa época cada novo acontecimento forçosamente exige a lei mais importante da dialética: a verdade é sempre concreta. (TROTSKY, 1934) 
Assim como Trotsky combatia a ideia que todo regime político na pré-guerra era fascista, caraterização antidialética realizada pelo stalinismo. Desde esse ponto de vista, para nós é central caracterizar sem simplificações o governo Bolsonaro. Quem repete que o governo Bolsonaro é fascista, hoje, é o PT na tentativa de capitalizar eleitoralmente.

O triunfo eleitoral de Bolsonaro expressou uma força política, social e material de um caráter qualitativamente diferente de outros contextos, contando com o apoio do conjunto das forças repressivas do Estado no marco de uma politização sob o controle das Forças Armadas, as igrejas evangélicas que, pela primeira vez, de forma homogênea transferem o voto no plano nacional. Mesmo sendo incialmente um filho não desejado do golpe, na semana anterior ao primeiro turno consegue o apoio do conjunto das classes dominantes, do capital financeiro internacional e de todas as instituições que sustentaram o golpe institucional, numa perspectiva de resolver a crise orgânica pela extrema direita, na tentativa de alterar, assim, a relação de forças entre as classes. De forma paradoxal, no momento que escrevemos este artigo, pela ajuda social, fundamentalmente nos estados do Nordeste, pela pandemia, cresce sua aprovação na base do lulismo, mas ainda é prematuro saber se isso é um fenômeno conjuntural ou construção hegemônica, mesmo que não se realize de um minuto para outro. Mas não deixa de ser importante destacar.

Em termos conceituais, de forma sintética, caracterizamos uma crise orgânica diferenciando, em termos gramscianos, este conceito de crise conjuntural. Desde o ano 2008 estamos frente à uma crise geral do capitalismo, econômica, política e social, que vai além de uma crise cíclica "normal", onde, depois de um período de expansão, se sucede um período de retração para depois tomar novo impulso gerando outro período de expansão capitalista. Deste ponto de vista, as perspectivas de crescimento da economia mundial são minúsculas até nos países capitalistas avançados, uma vez que a crise se inicia na principal potência imperialista mundial (Estados Unidos), que é o maior 
comprador do mundo e articula de forma desigual e combinada crises econômicas, políticas e sociais que se manifestam de forma particular em cada formação econômico-social. Dos Estados Unidos, vai para o Norte da África, no que foi conhecido como a "primavera árabe", depois a Europa e com o fim do boom das comodities, chega com força na América Latina a partir de 2013. Com a pandemia da COVID-19 no ano 2020 e a crise sanitária, essas tendências recessivas que já existiam no capitalismo mundial se aprofundam.

Bolsonaro assume a presidência no marco de um regime no qual os mecanismos da democracia burguesa "normal" estão cada vez mais subordinados a atores sem voto, como o autoritarismo judiciário ou dos próprios militares, esses com uma participação altíssima nos primeiros escalões do governo federal. Os objetivos desde o golpe institucional são claros: impor ataques profundos à classe trabalhadora e à população pobre, e continuar cortando direitos sociais e avançar nas privatizações.

Nesse sentido, para nós seria mais adequado, neste momento, considerar o governo de Bolsonaro como um governo pré-bonapartista, porque ainda não é um governo 100\% das Forças Armadas, como seria um governo de Mourão, nem é um governo fascista, mesmo que tenha ideias fascistas e fascistizantes, porque isso não depende da cabeça de Bolsonaro, de sua família ou de algum guru, senão das relações de forças materiais concretas na sociedade.

O pré-bonarpartismo nos permite entender hoje este tipo de governo, e isso não significa tirar um grama na necessidade da luta contra este governo, mas de entender de forma geral a nova configuração da classe trabalhadora que luta e para quê? E a necessidade da ação política da classe trabalhadora no plano nacional e internacional.

\section{Frente única operária ou frente ampla eleitoral?}

Como mencionamos na introdução, esses ataques às mudanças nas leis trabalhistas, à reforma da previdência, à lei de teto dos gastos, assim como, a velha lei de responsabilidade fiscal e a autonomia do Banco 
Central, em benefício do pagamento dos juros e da dívida interna, entre outros, realizados com a passividade das centrais sindicais, têm como objetivo mudar a correlação de forças entre as classes para garantir ainda mais os lucros do capital financeiro e de forma mais acelerada.

Se procura reconfigurar ainda mais a classe trabalhadora para fragmentar e poder explorar mais e melhor, dividindo entre trabalhadores formais e informais, aqueles trabalhadores que ainda tem certos direitos e os terceirizados, os empregados e desempregados, uberizando e precarizando ainda mais a classe e deixando sem perspectiva a grande maioria da juventude. Num país como o Brasil essa nova configuração da força de trabalho tem cor e gênero.

Dessa forma, a resposta tem que ser em diferentes níveis para passar de uma articulação corporativa a uma articulação política.

Em termos sindicais seria central unificar a todos os trabalhadores por local de trabalho, independentemente de seu tipo de contrato, formais e informais, terceirizados ou não, da mesma forma que articular as demandas de empregados e desempregados.

Mas isso ainda seria uma saída defensiva, é preciso, pelo lugar privilegiado que tem em alguns setores chave da sociedade, que os trabalhadores se constituam em partido político revolucionário e incorporem como suas as demandas do conjunto dos setores oprimidos da sociedade. Para isso, a classe trabalhadora tem que construir hegemonia, se constituir em caudilho as massas exploradas e oprimidas. E isso implica definir qual é a melhor tática de luta no marco de uma estratégia revolucionária.

Consideramos relevante diferenciar conceitualmente tática de estratégia.

Na perspectiva leninista entendemos a tática como a arte de orientar as operações isoladas, a direção dos combates parciais, e a estratégia como a arte de vencer, ligar os resultados ao objetivo da guerra. Nesse caso, a conquista do poder político pelo proletariado e a instauração de um governo operário, compreendida, como afirma Trotsky 
no Programa de Transição escrito em 1938, como uma forma popular de denominar a ditadura do proletariado.

Essa diferenciação conceitual entre tática e estratégia, desenvolvida por León Trotsky, a partir de um ponto de vista marxista revolucionário, no livro Lições de Outubro, é a seguinte:

Em política, entende-se por tática, por analogia com a ciência da guerra, a arte de orientar operações isoladas; por estratégia, a arte de vencer, isto é, conquistar o poder. Não fazíamos vulgarmente esta distinção antes da guerra, na época da II Internacional, limitando-nos à concepção da tática socialdemocrata. E não era por obra do acaso: a socialdemocracia tinha uma tática parlamentar, sindical, municipal, cooperativa, etc. A questão da combinação de todas as forças e recursos, de todas as armas para alcançar a vitória sobre o inimigo, não se levantava na época da II Internacional, pois esta não fixava como tarefa prática a luta pelo poder. Depois de um longo interregno, a Revolução de 1905 pôs novamente na ordem do dia as questões essenciais, as questões estratégicas da luta proletária, garantindo com isto enormes vantagens aos socialdemocratas revolucionários russos, quer dizer, aos bolcheviques. (TROTSKY, 1979, p. 12).

Depois Trotsky continua articulando a relação entre tática e estratégia afirmando que a primeira está subordinada a segunda.

Em 1917 começa a grande época da estratégia revolucionária, primeiro para a Rússia depois para toda a Europa. É evidente que a estratégia não impede a tática: as questões do movimento sindical, da atividade parlamentar, etc., longe de desaparecerem do nosso campo visual, adquirem agora uma importância diferente, como métodos subordinados da luta combinada pelo poder. A tática está subordinada à estratégia. (TROTSKY, 1979, p. 12).

Para Lenin e Trotsky só será possível atingir este objetivo com independência teórica e política, subordinando a tática à estratégia. 
Assim como diferenciamos tática de estratégia, é igualmente relevante diferenciar estratégia de grande estratégia. Isso aparece de forma muito clara no capítulo 7 do livro Estrategia socialista y arte militar de Emilio Albamonte e Matías Maiello, intitulado: Gran estratégia y revolución permanente.

Sendo que a estratégia liga os combates táticos, parciais para o fim político, a tomada do poder político pelo proletariado, como mencionamos acima, a grande estratégia entende que a conquista do poder num país passa a ser um resultado tático numa estratégia global para o comunismo, uma sociedade sem classes e sem Estado (ALBAMONTE; MAIELLO, 2017, p. 425).

A política de Frente Única Operária (FUO) é uma tática que foi aprovada no III Congresso da Internacional Comunista que se reuniu em junho de 1921, num contexto econômico de aprofundamento da crise, aumento do desemprego e de recomposição das forças capitalistas. Essa tática complexa se denominou Frente Única Operária (FUO), a qual era visualizada como a união na ação de todos os operários dispostos a lutar contra o capitalismo, procurando a máxima unidade possível de todas as organizações operárias em cada ação contra o capitalismo, unidade nas lutas, mas com independência política e liberdade de crítica. Colpeando juntos, mas marchando separados.

A FUO, de fato, era uma tática de unidade de ação, nesse momento com os socialdemocratas da II Internacional, a Internacional II e meia ${ }^{3}$, a Internacional Sindical de Amsterdam4, Holanda, e com grupos anarco-sindicalistas.

Mesmo que a da II Internacional, a Internacional II e meia prefiram acordos com a burguesia, o objetivo seria construir a unidade de ação e desmascarar frente aos trabalhadores aqueles que aniquilam a unidade, criticando suas direções. Para realizar essa tática no marco de uma estratégia revolucionária, era preciso ter clareza ideológica e homogeneidade para manter a autonomia política e não ceder às diferentes pressões oportunistas. 
Essa tática poderia se aplicar no Brasil na luta contra Bolsonaro, Mourão e os militares. Seria a unidade de ação de todos aqueles que são contra Bolsonaro e os ataques à classe trabalhadora na luta, com independência política entre organizações políticas e sindicatos e liberdade de crítica. Dessa forma, seria possível barrar os ataques de Bolsonaro, mas, também, acabar com o legado golpista.

Diferenciamos FOU de Frente Política eleitoral (FPE).

Como frente política eleitoral destacamos a conformação da Frente de Izquierda y de los Trabajadores (FIT) da Argentina, no ano 2011, que se transformará em Frente de Izquierda y de los Trabajadores Unidade (FIT-U) desde o ano de 2019. Essa FPE tem a característica de ser uma frente política eleitoral programática, de independência de classe, bem diferente que as opções neorreformistas, como a Siryza na Grécia ou o Podemos no Estado Espanhol, hoje administrando com o PSOE o imperialismo daquele país. A FIT é uma frente política 'anticapitalista de luta, integrada pelo Partido de los Trabajadores Socialistas (PTS), Partido Obrero (PO) e Izquierda Socialista (IS), no FIT-U se somou o Movimiento Socialista de los Trabajadores (MST). Mencionamos também que, para além de uma frente política eleitoral programática, a FIT é, sobretudo, produto de uma década de luta dos trabalhadores, atravessada por importantes experiências de luta de classes dos trabalhadores no país, começando a partir da recuperação de fábricas desde 2001, como é o caso da fábrica de cerâmicas Zanon, hoje Fábrica sem Patrões (FaSinPat), sob gestão operária desde 2001, a gráfica MadyGraf (ex-Donnelley) que também se encontra sob gestão operária desde 2014, além da longa batalha em Lear Corporation, o importante conflito da multinacional Kraft, em 2009, que se transformou no principal conflito operário durante o kirchnerismo, entre várias outras lutas, bem como a atuação no sindicalismo de base contra a burocracia sindical visando recuperar os sindicatos como instrumentos de luta dos trabalhadores, assim como o movimento de desempregados de anos anteriores. 
Isso se diferencia da ideia de frente ampla no Brasil que, na verdade, pretende reproduzir a política stalinista do VII Congresso da Internacional Comunista stalinizada, realizado em 1935, que é a política de frente popular. Uma política menchevique, elaborada por Stalin, onde os trabalhadores devem se subordinar a frações burguesas supostamente democráticas ou progressistas. Na verdade, na atualidade faz parte da utopia reformista do PT, procurando algum espaço sob o sol do golpe e dos golpistas, mão colocando as organizações de massas que dirigem a serviço da luta contra Bolsonaro, senão em função das eleições, fazendo alianças com figuras e partidos golpistas. Essa estratégia do PT é a forma de se opor a Bolsonaro, mas não na luta de classes, senão garantindo a sua obra econômica e a do conjunto dos golpistas. A ideia seria, ao caracterizar como fascista, realizar uma frente ampla policlassista para se opor a Bolsonaro, mas deixando intacto o legado econômico e seus ataques aos trabalhadores.

\section{Algumas propostas políticas transicionais para que a crise não seja paga pelos trabalhadores}

Apresentamos agora quatro propostas que poderiam permitir iniciar a reversão desses processos, em termos anticapitalistas e socialistas, para que a crise não seja paga pelos trabalhadores, como: a redução da jornada de trabalho sem redução de salários, a estatização de toda empresa que fecha sob controle dos trabalhadores, abrir os livros das empresas e a convocatória a uma Constituinte Livre e Soberana. Lógico que essas medidas políticas deveriam ser acompanhadas do não pagamento da dívida e a nacionalização dos bancos, centralização num banco único nacional e do comércio exterior.

Sobre a redução da jornada de trabalho sem redução de salários, Trotsky no Programa de Transição, publicado em 1938, trata desse tema, já que o capitalismo gerou duas calamidades econômicas: o desemprego e a carestia de vida, que exigem a articulação tanto de consignas transicionais, como de métodos de luta. Em relação a ca- 
restia de vida Trotsky propõe a escala móvel de salários, que significa que os contratos empregatícios assegurem o aumento automático dos salários de acordo com o aumento dos preços dos artigos de consumo. E contra o desemprego, seja estrutural ou conjuntural, propõe a escala móvel de horas de trabalho, na qual o trabalho disponível deve ser repartido entre todos os operários, mantendo a média do mesmo salário. (TROTSKY, 2008, p. 21-22).

Um dos objetivos dessa proposta é unir as fileiras dos trabalhadores e impor uma nova relação de forças que questione a própria existência da propriedade privada dos meios de produção. Parafraseando algumas palavras muito distantes - e salvando as distâncias se não pretendemos conquistar imediatamente a redução da jornada de trabalho e a distribuição de jornadas de trabalho, pelo menos começamos a conquistar um setor de trabalhadores para essas bandeiras. Não é pouco e, em momentos mais críticos, pode ser decisivo. (BACH, 2017 - tradução nossa).

Evidentemente que tal proposta gera sempre enormes debates, uma vez que tal medida se choca com os interesses dos capitalistas. Trostsky, em 1938, no referido programa, já alertava para o fato de os capitalistas e seus advogados tentarem convencer da impossibilidade destas reivindicações.

Os políticos tradicionais, seus advogados e os economistas burgueses argumentam que é algo utópico, no entanto, com a prerrogativa de gerar empregos, subsidiam empresas e reduzem os impostos empresariais, mas que na verdade não geram os empregos necessários, só beneficiam as empresas, bem como empregam de forma precária trabalhadores para trabalhar de domingo a domingo, 10 horas por dia, jovens precarizados em sua maioria. (LA IZQUIERDA DIARIO ARGENTINA-REDAÇÃO, 2017 - tradução nossa).

Em referência a estatização de toda empresa que fecha sob controle dos trabalhadores, principalmente para aquelas que fecham e demitem todos os seus trabalhadores, ou seja, é colocada sob a 
gestão dos seus trabalhadores e da comunidade, proibindo por lei as demissões, e distribuindo as horas de trabalho entre todos os trabalhadores; e para pôr fim aos exorbitantes lucros dos grandes empresários em cima das empresas de serviços públicos e baratear seus serviços para a população, junto com a defesa da nacionalização das empresas de serviços públicos, estratégicas, que foram privatizadas, como, por exemplo, empresas que controlam os recursos de hidrocarbonetos, todo o sistema de energia, transporte, etc., e vai além afirmando que essas devem ser geridas pelos seus trabalhadores com o controle popular que se daria da seguinte forma: por meio de votação direta os trabalhadores conformam os órgãos de direção e administração. Sendo central a participação de comitês de usuários populares. A perspectiva é que todos os trabalhadores tenham baixas taxas no caminho. Isso se reflete nas necessidades de luta do proletariado na época imperialista. Entendendo, nesse caso, que a única forma de garantir a diminuição dos preços, em relação sobretudo às empresas estratégicas, por exemplo, combustiveis e energia, é acabando com o lucro dessas empresas e colocando-as sob a gestão dos trabalhadores, das trabalhadoras e dos usuários.

Da mesma forma, a proposta de abrir os livros das empresas como parte de um plano de emergência mais geral, que se apresenta como necessidade para uma saída de fundo para a crise, como já mencionamos nos tópicos anteriores, como a expropriação das fábricas que ameacem fechar e demitir em massa; nacionalização das empresas de serviços públicos como forma de barrar os preço exorbitantes de serviços públicos essenciais, ambas sob controle operário; escala móvel de salário e horas de trabalho, reduzindo a jornada sem redução salarial. A abertura dos livros de contabilidade das empresas que ameacem fechar e, com isso, demitam todos os seus trabalhadores, é uma forma de garantir os postos de trabalho, e muitas dessas empresas, de forma fraudulenta, declaram falência para não arcar com certos custos, responsabilidades e suas consequências. Uma justificativa re- 
corrente é que o déficit financeiro da empresa é causado pelos "privilégios" dos trabalhadores, a abertura dos livros evitaria isto.

Por fim, a proposta de uma Assembleia Constituinte Livre e Soberana (ACLS), capaz de questionar todos os privilégios da casta política e que todos decidam o que é melhor para o país. Que os representantes possam serem revogados caso não cumpram com a função designada. Alguns temas para ser debatidos e votados: deixar de pagar a dívida pública; impostos sobre grandes fortunas; nacionalização dos bancos, uma vez que são os que organizam a fuga de capitais; pela reestatização sob gestão dos trabalhadores e controle popular de todas as grandes empresas estratégicas; eleições por voto popular de todos os juízes, e que os mesmos possam ter seus mandatos revogados; que todos os casos de corrupção sejam julgados por júri popular; separação da Igreja e do Estado; aborto legal, livre, seguro e gratuito.

Deve ser totalmente Livre para que os trabalhadores possam votar medidas para que os ricos paguem pela crise, numa tentativa de que não seja a classe trabalhadora que pague por ela através de ajustes brutais; que seja Soberana para que nenhuma instituição do regime possa mudar ou negociar o que nela se decida. Isso para diferenciar claramente, por exemplo, como por vezes se propõe no Brasil, de uma constituinte exclusiva, que tem por objetivo apenas reformar e restabelecer os poderes legislativo, judiciário e executivo.

No atual contexto de profunda crise e reconfiguração da classe trabalhadora, a ACLS é uma saída de emergência e democrática, a mais democrática dentro da democracia burguesa, que permitiria aos trabalhadores se opor aos pactos nas costas do povo. No marco de uma situação, no caso do Brasil, que não é revolucionária, permitiria avançar na experiência de milhões que ainda confiam na força do voto para mudar as coisas. Com base no trotskismo, a defesa de uma ACLS cumpre uma enorme função pedagógica para organizar as massas em torno de uma saída anti-imperialista ao evidenciar o choque entre os interesses 
de classe antagônicos, opondo os interesses dos trabalhadores e da população em geral aos interesses do grande capital, da burguesia.

Essas formam um conjunto de medidas/propostas transicionais que, apesar de serem justas, só poderão se concretizar efetivamente no socialismo, posto que encontrarão resistência, já que, como afirma Friedrich Engels, nenhuma classe que tem privilégios abandona a cena da história sem lutar. No Programa de Transição, na parte sobre a expropriação dos grupos de capitalistas, Trotsky enfatiza:

Apenas o ascenso revolucionário geral do capitalismo pode colocar a expropriação geral da burguesia na ordem do dia. O objetivo das reivindicações transitórias é preparar o proletariado para resolver esse problema. (TROTSKY, 2008, p. 31).

\section{Conclusão}

Em meio à crise capitalista que se aprofunda, e de forma desigual e combinada em cada formação econômico-social concreta, a partir do ano 2020 temos uma crise sanitária pela pandemia da COVID 19 que aprofunda a crise econômica, política e social que já estava em curso.

No âmbito de mudanças geopolíticas temos o fim do consenso globalizador no marco da crise que abriu passo a tentativas nacionalistas de extrema direita, como expressa Donald Trump nos USA, uma potência imperialista, e Bolsonaro no Brasil, num país com rasgos semicoloniais. Nesse marco, temos ataques à classe trabalhadora e uma nova configuração da mesma, a qual não tira seu papel no sentido de ocupar os setores estratégicos.

Depois de apresentar o governo Bolsonaro como pré-bonapartista, e não como fascista, e diferenciar conceitualmente tática de estratégia, entendemos que é central uma frente única operária de luta contra Bolsonaro, Mourão e os militares, para mudar não só os jogadores senão as regras do jogo. Depois de opor frente única operária a frente ampla, apresentamos um conjunto de propostas transicionais que poderiam fazer que a crise seja paga pelos capitalistas, para, desde a 
perspectiva da luta de classes, superar não só os ataques de Bolsonaro, senão também de Mourão, os militares e os golpistas e seu legado.

Finalmente, consideramos central que os trabalhadores se organizem construindo partidos revolucionários no plano nacional e internacional para reconstruir a IV Internacional a partir de um marxismo de centralidade estratégica.

\section{Referências}

ALBAMONTE, Emilio e MAIELLO, Matias. Estrategia socialista y arte militar. Buenos Aires: Instituto del Pensamiento Socialista; 2017.

BACH, Paula.; La jornada laboral, el reparto de las horas y la relación de fuerzas. La Izquierda Diario. Argentina, 9 ago. 2017. Disponível em: http://www. laizquierdadiario.com/La-jornada-laboral-el-reparto-de-las-horas-y-la-relacion-de-fuerzas. Acesso em: 30 06. 2020.

ENCELS, Friedrich. Anti-Durhing. São Paulo: Boitempo; 2015.

LA IZQUIERDA DIARIO ARGENTINA - REDAÇÃO. [Video] Del Caño: "Proponemos reducir la jornada laboral, con salario igual a la canasta familiar". La Izquierda Diario. Argentina, 20 jun. 2017. Disponivel em: https://www.laizquierdadiario.com/Video-Del-Cano-Proponemos-reducir-la-jornada-laboral-con-salario-igual-a-la-canasta-familiar. Acesso em: 12 out.2020.

MAIELLO, Matias; LIZARRAGUE, Fredy. Debate en el Frente de Izquierda: frente único y frente electoral. La izquierda Diario. Argentina, 12 jun. 2015. Disponivel em: https://www.laizquierdadiario.com/Debate-en-el-Frente-de-Izquierda-frente-unico-y-frente-electoral. . Acesso em: 30 06. 2020.

TROTSKY, León. Manifiesto a los trabajadores del mundo entero. In: El Programa de Transición y la fundación de la IV Internacional. Obras Escogidas 10; Buenos Aires/Ciudad de México: Ediciones IPS/Ediciones del Derecho al asilo Casa Museo León Trotsky.2017.

TROTSKY, León. Bonapartismo y fascismo. In: La lucha contra el fascismo en Alemania. Buenos Aires: Instituto del Pensamento Socialista; 2013.

TROTSKY, León. O Programa de transição. Documentos da IV Internacional. São Paulo: Edições ISKRA; 2008.

TROTSKY, León. As Lições de Outubro; São Paulo: Clobal editora, 1979. 


\section{Notas}

1 Gonzalo Adrián Rojas. Professor Dr. Ciência Política, Unidade Acadêmica de Ciências Sociais (UACS), Programa do Pós-graduação em Ciência Política (PPCCP) e no Programa de Pós-graduação em Ciências Sociais (PPCCS) da Universidade Federal de Campina Grande (UFCG), Campina Grande, Paraíba. Brasil. ORCID: https://orcid.org/0000-0003-2009-4772. E-mail: gonzalorojas1969@hotmail.com

2 Shimenny Ludmilla Wanderley Araújo. Socióloga. Mestre em Ciências Sociais pela Universidade Federal de Campina Grande (PPCCS/UFCG). Brasil. ORCID: https://orcid.org/0000-0003-2561-8328 E-mail: shimennyaraujo@yahoo.com.br'

3 A União de Partidos Socialistas para Ação Internacional (UPSAL) e conhecida também como a Internacional 2 e meia (I2M) ou Internacional de Viena (IV), foi fundada em 1921 em Viena, Áustria, sendo uma cisão da II Internacional. Estas se unem em 1923 na Internacional Operária e Socialista (IOS).

4 A Federação Internacional Sindical (FIS), também é conhecida como Internacional de Amsterdã (IA), mas tem sua origem em Copenhagen, Dinamarca em 1901. Na oitava conferência realizada em Zurich, Suíça, o Secretariado Sindical Internacional (SSI), se transforma em Federação Sindical Interacional (FSI) 